\title{
Ecological vulnerability analysis: a river basin case study
}

\author{
A. Ippolito ${ }^{1}$, S. Sala ${ }^{1}$, J.H. Faber ${ }^{2}$, M. Vighi ${ }^{1}{ }^{*}$ \\ ${ }^{1}$ Department of Environmental Sciences, University of Milano Bicocca, Piazza della Scienza 1, 20126 \\ Milano, Italy \\ ${ }^{2}$ Centre for Ecosystem Studies, Alterra, Wageningen UR, PO Box 47, 6700 AA Wageningen, The \\ Netherlands
}

\begin{abstract}
Assessing and quantifying ecosystem vulnerability is a key issue in site-specific ecotoxicological risk assessment. In this paper, the concept of vulnerability, particularly referred to aquatic ecosystems, is defined. Sensitivity to stressors, susceptibility for exposure and recovery capability are described as component of vulnerability of biological communities. The potential for habitat changes must also be considered in ecosystem vulnerability assessment. A procedure based on the application of an ecosystem vulnerability index is proposed. The method allows the assessment of vulnerability of riverine ecosystems to multiple stressors. The procedure is applied to two river systems in northern Italy: River Serio, subject to strong human pressure, and River Trebbia, in semi-natural conditions, as reference system. Macrozoobenthos is chosen as the indicator community. The actual quality of River Serio was evaluated as the result of the multiple stressor pressure on the reference system. Values and limitations of the approach are discussed.
\end{abstract}

Keywords: Ecological vulnerability assessment, river ecosystems, macrozoobenthos, river quality, multiple stressors.

\section{Introduction}

Ecosystem vulnerability is an underdeveloped concept in ecotoxicological risk assessment.

The objective of most procedures required by European regulations on dangerous chemicals is assessing the risk for "general" European ecosystems. For example, for plant protection products, the objective of the Pesticide Directive (Directive 91/414; EC 1991) is "the placing of plant protection products on the market" and, in this frame, assessing a potential danger for European aquatic and terrestrial ecosystems. The FOCUS (FOrum for the Co-ordination of pesticide fate models and their USe) group for pesticides developed a number of standard scenarios, assumed as representative of different agronomic and environmental characteristics of different European regions (FOCUS 2002). This approach allows assessing risk considering different environmental scenarios, however, many characteristics of real ecosystems are not taken into account.

The recently approved REACH (Registration, Evaluation and Authorisation of Chemicals, Regulation 1907/2006; EC 2006), establishing common rules for "new" and "existing" chemicals, is based on a Chemical Safety Report (CSR) describing exposure scenarios that may vary from "generic" to "very specific". Exposure scenarios must include risk management measures that ensure that the risks from the use of the substance are adequately controlled. However, environmental risk assessment is based on the comparison between a PEC and a PNEC, and the latter is traditionally derived from laboratory toxicity tests. Extrapolation of laboratory standard tests to the field situation is hampered by lack of information for sitespecific representative species, as well as for interactions related to structure and functioning of the ecosystem (indirect effects, homeostatic capability, recovery mechanisms, etc.). Therefore, in standard risk assessment procedures the community characteristics of actual ecosystems are poorly considered, if at all.

However, ecotoxicological risk assessment is not only required for general objectives, such as the continental-scale regulation of chemical substances. The scale of environmental management is usually smaller and requires assessment on relatively small geographic units (hydrographic basins, local administrative units, etc.), where site-specific approaches are required for protecting specific ecosystems. The responses of different ecosystems to a particular stressor may be very different. Therefore, information on the characteristics of potentially endangered ecosystems is essential in site-specific risk assessment. 
Site-specific approaches are also required by the Water Framework Directive (WFD, Directive 2000/60; EC 2000) asking for tools capable to describe and assess the site-specific ecological status of European water bodies. The ecological status of aquatic ecosystems is the result of natural environmental conditions and of the pressure of anthropogenic stressors. The deviation of ecosystem status from natural (reference) conditions is a function of the intensity of stressors and of ecosystem vulnerability. It follows that assessing sensitivity and vulnerability of ecological systems is a key issue in ecotoxicology. However, in spite of this relevance, few examples of vulnerability assessment have been presented in the literature. A state of the art overview is described by De Lange et al. (2010).

Ecological vulnerability must be assessed at different hierarchical levels (population, community, ecosystem, landscape). Some definitions are given by De Lange et al. (2010). The problem is not easy; particularly if one considers that the responses of different populations are generally different as a function of different stressors. Moreover, ecosystem vulnerability considers the response at the community level. The characteristics of a community are not merely the sum of the characteristics of individual populations; structure and function of the community are also regulated by emergent properties that are not easily described and predicted from lower hierarchical levels. According to van Straalen (2003), the community is the entity with the lower predictability, among the different ecological hierarchical levels. Assessing ecosystem vulnerability represents a challenge for modern ecotoxicology.

In this paper, the concept of ecosystem vulnerability is elaborated, with particular focus to aquatic ecosystems. A numeric "Vulnerability index" is developed, in order to evaluate the potential response of ecosystem features to multiple stressors.

The index has been applied to the case study of two river ecosystems subject to different levels of human pressure. The response of the aquatic communities is discussed as a function of their vulnerability to multiple stressors.

\section{Vulnerability of ecosystems: definition and specific elements}

Ecosystem vulnerability assessment is a complex process that needs a number of factors to be considered. In this paper, vulnerability is the set of properties of an ecosystem that determines its potential for being damaged by a specific stressor.

Each ecosystem consists of a community of species living in a specific biotope (characterised by its own physical, chemical, climatic, geographical and morphological features). Therefore ecosystem vulnerability assessment should comprise both community and habitat aspects.

Both evaluations are closely related: if a stressor can induce relevant habitat changes, then this could result in direct or indirect disturbance of the biological community, and vice versa.

\subsection{Community vulnerability}

Vulnerability assessment of a biological community must start from the analysis of three characteristics of the different populations:

- Susceptibility to exposure

- Sensitivity for a particular stressor

- Recovery potential at population and community levels

While species are the units that react first to the stressor on the basis of their specific traits, the impact to the community follows from population responses and changes in interspecific relations.

The final objective of environmental management is protecting structure and function of communities and ecosystems. Thus, the assessable characteristics of a biological community should not only comprise population characteristics, but preferably also include emerging properties and relationships and interaction among populations that determine community function and structure.

\subsubsection{Susceptibility to exposure assessment}

The Predicted Environmental Concentration (PEC) in a given compartment (water, air, soil) is the most frequently used exposure indicator in risk assessment. In some cases, the time variability of the PEC may be accounted for. Nevertheless species have intrinsic traits (behavioural, physiologic, metabolic, etc) that determine the probability for exposure. 
Stressors characterised by discontinuous exposure may have a fully different effect on organisms continuously living in a given compartment in comparison with species with a polymorphic life cycle, changing living environment from one life stage to another (e.g. aquatic larvae of insects).

Other behavioural factors may also be relevant, such as mobility, seasonal behavioural changes, etc. All such factors together determine the probability to be exposed to a stressor. At present, precise criteria for assessing and quantifying the susceptibility to exposure have not been developed. A more detailed study on physiological and behavioural traits relevant in different exposure conditions would be necessary.

\subsubsection{Sensitivity assessment}

The sensitivity of different species in the community could be represented in probabilistic terms using the Species Sensitivity Distribution (SSD) method (van Straalen and Denneman 1989; Posthuma et al. 2002). Lack of experimental data on community species could be overcome trying to predict responses of different species to a specific stressor on the basis of some biological traits (Baird 2007). Another system to predict effects are QICAR (Quantitative Interspecific Chemical Activity Relationships, Tremolada et al. 2004; Dimitrov et al. 2000). However, in risk assessment procedures, the SSD approach is developed on the basis of data available in the literature on organisms representative of a generic (aquatic or terrestrial) environment. For site-specific sensitivity assessment, SSD may be applied to assess the potentially affected fraction of the community, but cannot predict the actual species at risk.

Secondly, the sensitivity of a community is not a simple combination of the sensitivity of populations. An important point is evaluation of emergent properties and indirect effects, i.e., consequences on structure and on functioning of the community determined by alteration of relationships between populations (competition, predation, etc) after a disturbance. On this topic, considered one of the more complex aspects of modern ecotoxicology, only little methodology is presented in literature.

\subsubsection{Recovery capability assessment}

Sensitivity is an expression of resistance, but does not give any information about the response in the time after exposure. The assessment of resilience, i.e. the capability of a system to return in the pristine state of structural and functional organization after an alteration induced by a stressor, is particularly important if exposure is not continuous or not constant.

While functional recovery is due to feature of the whole system, structural recovery depends on the resilience of each population in the community. Population recovery depends on genotypic and phenotypic properties of individuals (age, sex and biomass distribution, fecundity, etc) and on collective species properties (metapopulation structure, mobility, territoriality, seasonality, iteroparity, etc).

As for susceptibility to exposure, precise criteria for a quantitative assessment of recovery capability are not available. However, for a qualitative preliminary assessment, some relevant traits are the reproductive capability, the biotic potential, the length of the life cycle, the capability for genetic, physiologic and behavioural adaptation.

\subsection{Habitat vulnerability assessment}

Ecosystem vulnerability assessment is the result of the previous community vulnerability assessment and the habitat vulnerability. In this context, habitat vulnerability represents the intrinsic predisposition of a biotope to be altered by natural or anthropogenic stressors, considering both biotic and abiotic factors.

To assess habitat vulnerability, qualitative criteria should consider issues due to available space reduction, structural and morphological changes, alteration of physical and chemical conditions as well as modification of microclimate. 


\subsection{Vulnerability assessment and ecological quality}

One of the requirements of the Water Framework Directive is the assessment of reference conditions in order to classify ecological quality of water bodies. According to the WFD (EC 2000) the ecological quality of a water body is defined as follows:

- High ecological status: The values of the biological quality elements for the surface water body reflect those normally associated with that type under undisturbed conditions and show no, or only very minor, evidence of distortion.

- Good ecological status: The values of the biological quality elements for the surface water body type show low levels of distortion resulting from human activity, but deviate only slightly from those normally associated with the surface water body type under undisturbed conditions.

Therefore, high ecological status, representing the reference condition, is characteristic for a water body where human pressure is absent or negligible and the biological community is typical for pristine conditions. Structure and functions of such a community depend on natural environmental factors and are different in different typologies of water bodies. It follows that reference conditions must be described for all the different typologies of a water body and for the different European ecoregions.

The set up of water body typologies and the definition of reference conditions is one of the objectives of the European Common Implementation Strategy for the Water Framework Directive. The definitions, methods, principles and criteria to be used for establishing reference conditions for the various typologies and for setting boundaries between high, good and moderate ecological status for inland surface waters are described in a specific Guidance Document (EC 2003).

The vulnerability of the communities typical for the different reference water bodies may be substantially different in relation to different stress factors. For example, the reference community of a cold mountain creek would be more vulnerable to oxygen depletion in comparison with those typical for a warm lowland river. Therefore, assessing the vulnerability of reference communities to potential stressors would be relevant to attain WFD standards.

\section{Methodological approach}

In this paper, a method to assess river ecosystem vulnerability is developed. As a first step, a general framework provides a qualitative description of the processes involved in the assessment. In a second step, a preliminary quantitative scoring system is proposed. The method is based on a stepwise procedure and may be applied with different levels of detail, depending upon the information available and on the requested level of refinement.

\section{Step 1. Characterizing different river typologies, from spring to mouth}

The first step of the procedure may be obtained by applying the Huet model (Huet 1949), based on hydromorphological features (slope, river width), that divides rivers in 4 typology classes of water body (from high mountain to lowland river). The Huet model has been applied for mapping pesticide risk in Italian river basins (Sala and Vighi 2008).

A more detailed system of classification (RIVPACS) is provided by Wright et al. (2000). It is derived from four predictors (latitude, longitude, drainage area, and stream-channel slope).

The Annex II of the WFD proposes a system based on a list of main features:

- Distance from spring (indicator of the extent of water body)

- Morphology of riverbed

- Perennity and persistence of the flow

- Origin of water body

- Possible influence of watershed upstream

The WFD approach may lead to a large number of typologies; a rationalization may be needed here for practical purposes.

Among the three methods, the choice is related to the availability of hydromorphological data and to the required resolution. 


\section{Step 2. Reference water body}

The actual community of a polluted river has been modified as a result of the impact determined by one or multiple stressors over time. However, management aims to establish and protect the potentially highest ecological quality. A suitable reference typology in natural or semi-natural conditions is required to perform vulnerability assessment. A proper selection of reference river should consider several characteristics like: length, extent of watershed, geographical position, average flow rate, average slope, etc.

\section{Step 3. Characterizing biological communities}

Each river segment (river typologies identified in Step 1, from here indicated with r.s.), is characterized by a potential biological community. The River Continuum Concept (Vannote et al. 1980) suggests a theoretical model where different species are distributed as consecutive Gaussian curves, the maxima coinciding with optimum habitat conditions of the species.

The knowledge of some characteristics of a specific ecosystem allows focusing on the populations that are more representative or that play a determinant role in the system (keystone species). This is a tentative, preliminary approach, because, up to date, more precise approaches capable to characterize the whole community are lacking.

Macrobenthos community is an excellent indicator of water quality. The EBI (Extended Biotic Index) is one of the most common water quality indicator (Woodiwiss 1964) routinely used since a long time in monitoring campaign. Different taxa cover several trophic levels and some of their characteristics (sensitivity to oxygen depletion as well as to some toxic chemicals, etc.) are quite well known.

\section{Step 4. Characterizing stressors}

Each event or process that can induce a change in the structure or functioning of a biological system must be considered a stressor. As vulnerability is not an absolute quality but is related to a particular stressor, vulnerability assessment has to be considered stressor-specific. Within this paper, vulnerability is assessed for each single stressor, even if one must be aware that combined stressors and interactions among stressors should be taken into account in a further development of the procedure.

Characterization of possible stressors acting on ecosystems should be developed with a qualitativequantitative approach. That could be obtained following an adaptation of DPSIR, the causal framework for describing the interactions between society and the environment adopted by the European Environment Agency: Driving forces, Pressures, States, Impacts, Responses. (EEA 2009). It has been chosen because of its proven appeal to policy makers (Stanners et al. 2007) and applied at some extent in the WFD context (Borja et al. 2006).

Starting point are the driving forces (D): urban, agriculture, industry, hydromorphological factors, others (landfill, climate change, invasive species, etc). These produce pressure (P) generating stressors able to modify the state (S) of the water body. Impact (I) is related to potential alteration due to the combination of vulnerability and magnitude of stressors (as explained in par 4.6). Responses (R) have to be developed by further phases of risk management and mitigation.

Every stressor must be considered individually. Characterization of potential stressors should take into account:

- Variability in time (continuous, intermittent, pulse, etc)

- Variability in space (point source, diffuse source, fixed, mobile, etc)

- Typology (chemical, physical, biological, etc)

Step 5. Evaluation of vulnerability

Evaluation of ecosystem vulnerability to a specific stressor is performed according to the scheme of Figure 1. Each component of vulnerability (sensitivity, recovery capability, susceptibility to exposure and potential for habitat changes) is evaluated individually for each potential stressor. 


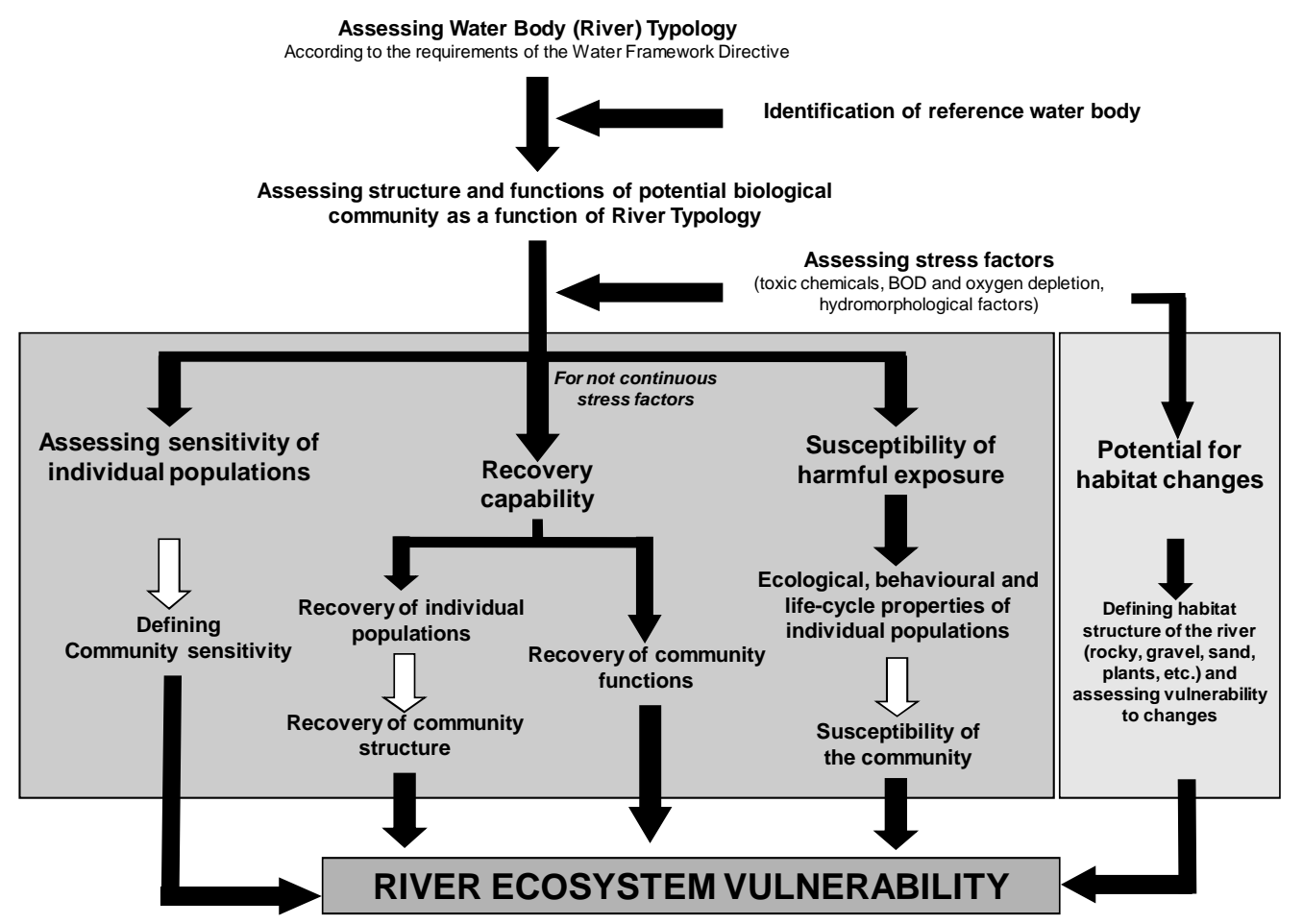

Figure 1 General scheme for river ecosystem vulnerability assessment. Left box is referring to community vulnerability assessment, while right box indicates habitat vulnerability assessment. Both evaluations are closely related, as one stressor acting on habitat could have indirect effects on the community and vice versa (Long term impacts, De Lange et al. 2010). White arrows indicate most critical issues arising at the change of scale from population to community level.

A simple scoring system from 0 to 3 has been developed to estimate the influence that a potential stressor can produce on a given component of the vulnerability (Table 1). Note that vulnerability is positively related to exposure susceptibility, sensitivity, and habitat alteration, while recovery capability contributes inversely.

Table 1 Scores attributed to the components of ecosystem vulnerability.

\begin{tabular}{lll}
\hline \hline Scores & Influence on Se, Su, HA* & Influence on $\mathbf{R}^{*}$ \\
\hline 0 & No influence & High influence \\
1 & Low influence & Medium influence \\
2 & Medium influence & Low influence \\
3 & High influence & No influence
\end{tabular}

*Se: Sensitivity; Su: Susceptibility of exposure; R: Recovery capability; HA: Habitat alteration.

A vulnerability assessment on a certain community has to cope with a lack of information at community level, so an expert judgment is required to provide a synthetic assessment on the community derived from exiting literature and data at population level. Some details on the procedure used for the scoring in the present case study are described in section 4.5.

Scores are used as inputs for the development of the following "Vulnerability index":

$$
V_{x}=\frac{S e_{x} \times S u_{x}}{1+R_{x}}+H A_{x}
$$

Where:

$\mathrm{V}_{\mathrm{x}}=$ Vulnerability of ecosystem to stressor $\mathrm{X}$

$\mathrm{Se}_{\mathrm{x}}=$ Score attributed to the influence of the stressor X on the Sensitivity of the community

$\mathrm{Su}_{\mathrm{x}}=$ Score attributed to the influence of the stressor $\mathrm{X}$ on the Susceptibility to exposure 
$\mathrm{R}_{\mathrm{x}}=$ Score attributed to the influence of the stressor $\mathrm{X}$ to Recovery capability

$\mathrm{HA}_{\mathrm{x}}=$ Score attributed to the influence of the stressor X on the Habitat Alteration

The index ranges from 0 (ecosystem not vulnerable to stressor) to 12 (ecosystem highly vulnerable to stressor). Community vulnerability is expressed by the first term of the index, while the second term expresses habitat vulnerability. Ecosystem vulnerability derives from the sum of these two components.

The equation assumes that community vulnerability varies linearly with sensitivity (Se) and with susceptibility to exposure ( $\mathrm{Su}$ ), because these are the elements that determine the immediate response of a community to a stressor. Resilience could mitigate alteration caused by the stressor, but only in a longer timescale. That is why $\mathrm{R}$ parameter could never bring to zero community vulnerability values if $\mathrm{Se}$ and $\mathrm{Su}$ are not null. When susceptibility to exposure or sensitivity is zero, community vulnerability is null and ecosystem vulnerability is only determined by habitat changes. When recovery capability is zero, community vulnerability is highest, as a function of Se and $\mathrm{Su}$.

Most ecosystems are potentially affected by several simultaneous stressors, acting separately or in interaction. The index should be applied to all the stressors identified in the river, according to the list of Step 4. An example of multistress vulnerability scheme is shown in Table 2. The table is a simplification of the potential stressors corresponding to different pressures. For example urban sewage may contain a number of toxic chemical(pharmaceuticals, detergents, etc.). In this assessment, only the major stressors have been considered.

According to the DPSIR scheme, the impact (I) is the combination of ecosystem vulnerability and the magnitude of the hazard produced by the stressor. The probability of impact determines the risk.

Table 2 Example of application of vulnerability assessment to a real ecosystem. Only the main stressors have been considered. The empty boxes should be filled according to the scoring system of Table 1 . The output of this scheme is a list of scores indicating ecosystem vulnerability referred to each stressor considered.

\begin{tabular}{|c|c|c|c|c|c|c|}
\hline \multirow[b]{3}{*}{ Driving force } & \multirow[b]{3}{*}{ Pressure } & \multirow[b]{3}{*}{ State } & \multicolumn{4}{|l|}{ Ecosystem Vulnerability } \\
\hline & & & Community Vulnerabilit & & & Habitat Vulnerability \\
\hline & & & Susceptibility to exposure & Sensitivity & $\begin{array}{l}\text { Recovery } \\
\text { capability }\end{array}$ & $\begin{array}{c}\text { Potential Habitat } \\
\text { Alteration } \\
\end{array}$ \\
\hline Urban & Urban sewage & Oxygen depletion & & & & \\
\hline Industrial & Wastewater & Chemical PEC & & & & \\
\hline Agricultural (crop) & Pesticide & Chemical PEC & & & & \\
\hline Agricultural (animal farms) & Manure & Oxygen depletion & & & & \\
\hline Hydromorphological & Flow rate alteration & Reduction of flow & & & & \\
\hline
\end{tabular}




\section{Application to case study (River Serio - River Trebbia)}

The method was applied to two river systems of northern Italy: River Serio, subject to high pressure from multiple stress factors, and River Trebbia, in semi-natural conditions, assumed as reference system. The vulnerability assessment procedure was applied to the macrobenthos community of River Trebbia, while macrobenthos of River Serio has been assumed as the resulting community as a consequence of the pressure of multiple stressors.

\subsection{Characterizing different river typologies, from spring to mouth}

According to the Annex II of WFD, five different river typologies have been identified from spring to mouth on the basis of some hydrological and morphological feature. So, the water bodies were divided into five river segments (r.s.) which have been considered comparable in the two rivers (Figure 2). Each r.s. corresponds to a sector of the watershed.

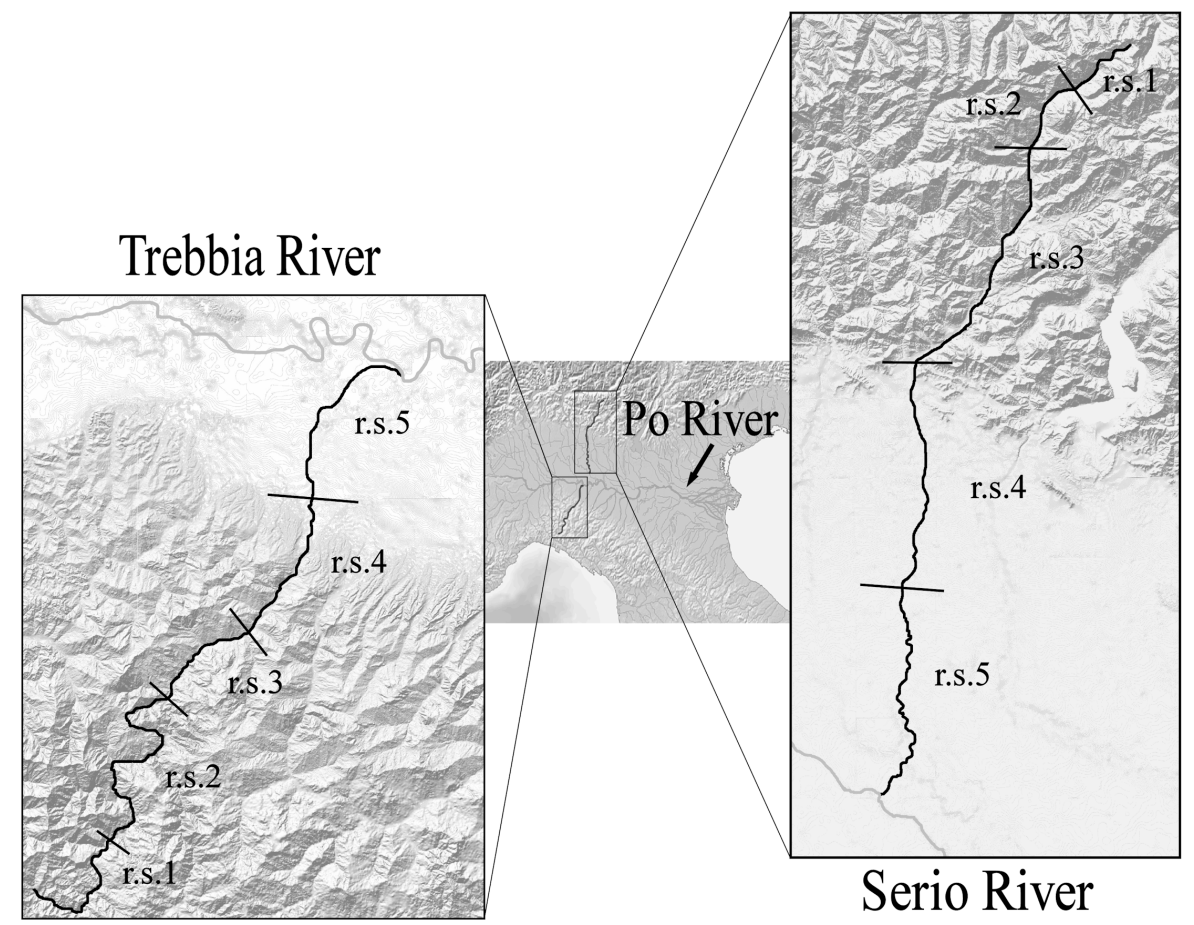

Figure 1 Identification of 5 river segments related to water body typologies on River Serio and River Trebbia from spring to mouth.

\subsection{Finding reference water body}

The two rivers are in the same climatic area, are comparable for morphological and hydrological characteristics (Table 1 in Appendix 1) and a comparable sequence of ecosystem typologies can be identified: both originate in mountains, flow through hills and then, for a large extent, in the Po Valley. Both rivers belong to the Po basin, and that makes them comparable even on a geographical point of view (Figure 2).

On the contrary, human pressure is extremely different. River Serio is subject to relevant urban, industrial and agricultural emissions. Moreover, water use for electric power production and agriculture irrigation, poses serious flow rate problems. River Trebbia presents a low human pressure and it is still in semi-natural conditions. The watershed is considered of high natural value as confirmed by the presence of a SCI (Site of Community Interest) from Perino to Bobbio, in r.s. 3. Therefore, River Trebbia has been chosen as a reference system.

The ecological status of River Serio is changed since a long time: the communities present now in the river are derived from pristine natural communities that should be similar to those of River Trebbia.

The aim of this case study is to assess vulnerability of the macrobenthos communities of River Trebbia, assumed as the potential pristine communities of River Serio, toward effective stressors acting (or that have 
been acting) on the riverine system. The comparison with the present community of River Serio would provide an example of the changes likely to occur as a function of vulnerability and of intensity of stressors.

\subsubsection{Community characterization}

Monitoring data on macrobenthos community (EBI - Extended Biotic Index - values, presence of different taxa, number of systematic groups for each taxon) have been obtained from ARPA (Agenzia Regionale per la Protezione dell'Ambiente - Regional Environmental Protection Agency) Emilia Romagna and Provincia di Genova for river Trebbia, from ARPA Lombardia and Provincia di Bergamo for River Serio (ARPA 2009; Provincia di Bergamo 2001; Provincia di Genova 2003). Data refer to 11 sampling stations on River Trebbia and 7 sampling stations on River Serio, covering all identified r.s. (Figure 3). In both rivers monitoring data were available for 9 sampling years (from 2000 to 2008). No time trends were observed, so the composition of macrobenthos reported in Table 3, represents simple arithmetical averages of abundance of systematic groups for each taxon in the 9 sampling years. 


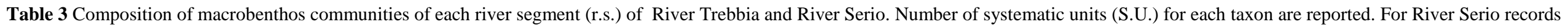
of 3 stations belonging to segment 3 have been kept separated because a clear gradient is present. Sums of systematic units consider even minor groups not reported in the table.

\begin{tabular}{|c|c|c|c|c|c|c|c|c|c|c|c|c|c|}
\hline \multicolumn{14}{|c|}{ RIVER TREBBIA } \\
\hline r.s. & Plecoptera & Ephemeroptera & Tricoptera & Coleoptera & Odonata & Diptera & Crustacea* & Gasteropoda & Oligochaeta & Tricladae & Heteroptera & S.U. & EBI \\
\hline 1 & 4.3 & 8 & 5.2 & 2.2 & 0 & 7.3 & 0 & 1 & 1.7 & 0.3 & 0 & 30 & 10.5 \\
\hline 2 & 3 & 4.7 & 4.1 & 2.5 & 0.5 & 5.6 & $0.3(0.0 ; 0.3)$ & 0.3 & 2 & 1 & 0.1 & 24 & 10.6 \\
\hline 3 & 2.3 & 5 & 2.8 & 1.8 & 1.1 & 4.3 & $0.1(0.0 ; 0.1)$ & 0.1 & 1.4 & 0.6 & 0.3 & 19.7 & 9.1 \\
\hline 4 & 2.2 & 5.5 & 3.1 & 2 & 0.9 & 4.4 & $0.4(0.0 ; 0.4)$ & 0 & 1.2 & 0.5 & 0 & 20.4 & 9.5 \\
\hline 5 & 1.5 & 4.4 & 1.3 & 0.7 & 0.3 & 2.8 & $0.5(0.0 ; 0.5)$ & 0.1 & 1.2 & 0 & 0 & 13 & 7.9 \\
\hline
\end{tabular}

\section{RIVER SERIO}

\begin{tabular}{lllll}
\hline 1 & 3 & 2 & 2 & 3 \\
2 & 2 & 3 & 2 & 1 \\
& 1.2 & 2.1 & 1.6 & 0.4 \\
3 & 0 & 1.1 & 0 & 0 \\
& 0 & 1.3 & 0 & 0 \\
4 & 0 & 1 & 0 & 0 \\
5 & 0 & 1 & 0.7 & 0.2
\end{tabular}

$\begin{array}{ll}0 & 3 \\ 0 & 5 \\ 0 & 3.1 \\ 0 & 2.2 \\ 0 & 2 \\ 0 & 118 \\ 0.2 & 1.4\end{array}$

$\begin{array}{lll}3 & 0 & 1 \\ 5 & 0 & 1 \\ 3.1 & 0 & 0.6 \\ 2.2 & 0 & 0.8 \\ 2 & 0 & 1.1 \\ 1.8 & 0.1(0.1 ; 0.0) & 0.3 \\ 1.4 & 1.4(0.8 ; 0.6) & 1.5\end{array}$

0.6
0.8
0.1
1.5

2
0
1
1.1
1.1
1.3
1

\begin{tabular}{ll|ll}
1 & 0 & 17 & 10 \\
0 & 0 & 14 & 8 \\
0 & 0 & 10 & 6.9 \\
0 & 1 & 6.2 & 4.7 \\
0 & 0.9 & 6.4 & 4.9 \\
0.1 & 0.7 & 5.3 & 4.2 \\
0.3 & 1.4 & 9 & 5.8
\end{tabular}

* numbers in brackets are the systematic units of Asellidae and Gammaridae respectively. 

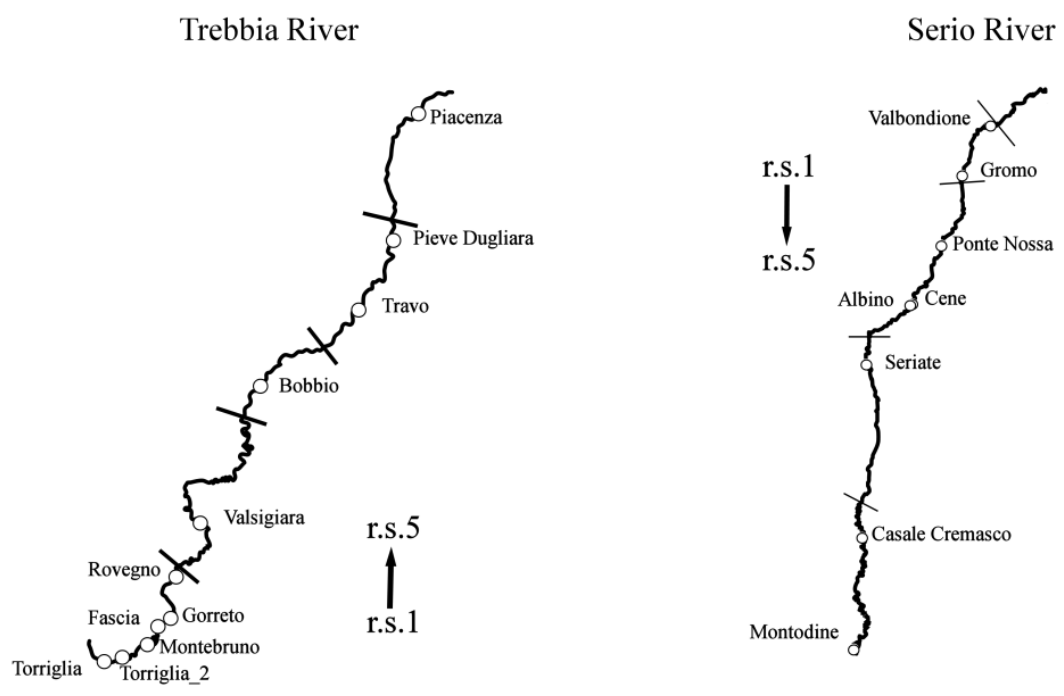

Figure 3 Position of the different macrozoobenthos sampling stations on both rivers.

\subsection{Stressor characterization}

Five drivers have been considered: Urban, Industrial, Agricultural (crop), Agricultural (animal farms), Hydromorphological. For Urban and Agricultural (animal farms), the combined action of organic sewage and related solid suspended matter has been considered. For the Industrial driver, only generic toxicity of chemical substances has been considered. For Agricultural (crop), only toxicity of plant protection products (especially insecticides) have been considered. The Hydromorphological driver is referring to flow rate alteration (reduction of natural flow, no consideration have been made about increase of natural flow). Urban, Industrial and Agricultural (animal farms) produce continuous stressors, while Hydromorphological and Agricultural (crop) produce discontinuous stressors. All driving forces listed in Table 2 are present, with different intensity, in River Serio.

\subsection{Evaluating vulnerability}

For each r.s., the vulnerability of the reference community to the five stressor clusters, listed in Table 2, has been assessed according to the vulnerability index of equation 2.1 (Table 4).

$1^{\text {st }}$ segment. Two third of the reference community (Table 3) is represented by taxa particularly sensitive to the oxygen concentration, so the community is highly sensitive to "urban" and "animal farms". Susceptibility to exposure is highest because urban and animal farms wastewaters are always present during the year and could affect each part of the river ecosystem. Influence on recovery is high as these stressors are continuous, so recovery cannot occur. Habitat could be significantly altered by solid particulate matter in a river typology where sediment is usually poor.

As for "industrial" stressor, sensitivity to toxic input should be relevant but not very high, as a good number of non-arthropods, relatively resistant to toxic chemicals, is present. Furthermore no sensitive crustaceans are present. No habitat alteration should be produced.

Agricultural stressors are discontinuous, so susceptibility to exposure is lower than others stressors and recovery is possible. All species considered are characterized by r-strategy with high reproductive potential, so recovery capability is high. Solid deposition producing habitat alteration is possible.

Hydromorphological issues are generally related to flow rate alteration producing a reduction of habitat. Habitat reduction should have species-specific effects that could be related to life stage of individuals. Those effects may affect the population density and may lead to further complication. However, at this stage we considered a generic effect on all macrobenthos taxa.

Moreover, reduced dilution increases the concentration of toxic substances. Richness of species in this segment requires a large number of different habitats, so influence of habitat reduction is very high. Susceptibility to exposure has been evaluated as intermediate because it depends on the relation between the 
distribution of critical flow over the year and the growing rate of singles populations. This kind of stressor is discontinuous, so recovery is possible.

$2^{\text {nd }}$ segment. Community and habitat are substantially the same as the first segment, so vulnerability is always the same.

$3^{r d}$ segment. The number of total systematic units in this segment has been reduced by one third (from 30 to less than 20), so habitat requirements should be reduced. Furthermore the river became wider and deeper so alteration in flow rate should have less influence on the community.

$4^{\text {th }}$ segment. The presence of crustaceans (particularly Gammaridae) increases sensitivity to agricultural stressor (particularly to insecticides) from 2 to 3 . Habitat alteration produced by urban or agricultural activities reduces its influence since natural quantity of sediments increases a lot.

$5^{\text {th }}$ segment. Sensitivity to urban and animal farms drivers diminishes as the number of systematic units particularly sensitive to oxygen depletion decreases (Plecoptera, Tricoptera, Ephemeroptera).

Since the total number of species decreases, less variability of habitat is required while river in this segment has the biggest average flow rate. So influence of water flow alteration on the habitat vulnerability decreases.

\subsection{Validation of vulnerability assessment through macrobenthos data}

The effect of actual stressors present in each segment of River Serio related to the vulnerability of the reference communities determined on River Trebbia (Table 4) can be checked by examining the present macrobenthos community of Serio. A quantification of the magnitude of the actual stressor is needed in this phase.

Agriculture (crop) - The intensity of the stressor has been estimated calculating the agricultural surface. Land use is reported in Table 5 and is divided in five classes: agriculture (all permanent and non permanent crops); industry (industrial, commercial, and handicraft activities); urban; other - possible stressors (hospital, mining, road and infrastructure, airport); other - no stressors (forest, uncultivated, grassland, meadow).

In Serio watershed, crops are mainly corn and other cereals. So, the main stressors are: pesticide use (mainly herbicides) and manure/fertilizer that may affect the oxygen demand. In Appendix 1 the maps of land use and the number of agricultural enterprises for each river segment are presented.

Agriculture (animal farms) - Animal farms are present in each river segment, particularly in segments three and four. Figure 4 shows the animal farm density, expressed as number of farms per $\mathrm{km}^{2}$, in each river segment of River Serio. The main stressor could be the release of organic matter, in the form of manure, and the related increase in oxygen demand.

Urban - The magnitude of the stressor is related to the total population present in the watershed $(411,217$ inhabitants). In Figure 4 the distribution of population density for each segment of the river is shown. Even if wastewater treatments plants are present, a relevant residual organic load has to be taken into account. A precise quantification is difficult.

Industrial - Industrial wastewater quality is a function of industrial typology. In the Serio watershed, 24,3\% of the enterprises are in construction sector, 23,1\% are retailers (shops and wholesale), 16,2\% are manufacturing, mainly textile, activities. In Appendix 1, the distribution of industrial activities is reported. Therefore, in the watershed the main industrial stressor may derive from manufacturing activities. The density of manufacturing activities in each watershed portion is shown in Figure 4, the distribution of all activities is provided in Figure 2 of Appendix 1. 
Table 4 Vulnerability assessment for each river segment and each kind of driver.

\begin{tabular}{|c|c|c|c|c|c|c|c|c|c|c|c|c|c|c|c|c|c|c|c|c|c|c|c|c|c|}
\hline \multirow[b]{2}{*}{ Stressor Drivers } & \multicolumn{5}{|c|}{ River segment 1} & \multicolumn{5}{|c|}{ River segment 2} & \multicolumn{5}{|c|}{ River segment 3} & \multicolumn{5}{|c|}{ River segment 4} & \multicolumn{5}{|c|}{ River segment 5} \\
\hline & Su & Se & $\mathbf{R}$ & HA & $\mathbf{V}$ & Su & Se & $\mathbf{R}$ & HA & $\mathbf{V}$ & Su & Se & $\mathbf{R}$ & HA & $\mathbf{V}$ & Su & Se & $\mathbf{R}$ & HA & $\mathbf{V}$ & Su & Se & $\mathbf{R}$ & HA & $\mathbf{V}$ \\
\hline Urban & 3 & 3 & 0 & 2 & 11 & 3 & 3 & 0 & 2 & 11 & 3 & 3 & 0 & 2 & 11 & 3 & 3 & 0 & 1 & 10 & 3 & 2 & 0 & 1 & 7 \\
\hline Industrial & 3 & 2 & 0 & 0 & 6 & 3 & 2 & 0 & 0 & 6 & 3 & 2 & 0 & 0 & 6 & 3 & 2 & 0 & 0 & 6 & 3 & 2 & 0 & 0 & 6 \\
\hline Agricultural (crop) & 2 & 2 & 3 & 2 & 3 & 2 & 2 & 3 & 2 & 3 & 2 & 2 & 3 & 2 & 3 & 2 & 3 & 3 & 1 & 3 & 2 & 3 & 3 & 1 & 3 \\
\hline Agricultural (farm) & 3 & 3 & 0 & 2 & 11 & 3 & 3 & 0 & 2 & 11 & 3 & 3 & 0 & 2 & 11 & 3 & 3 & 0 & 1 & 10 & 3 & 2 & 0 & 1 & 7 \\
\hline Hydromorphological & 2 & 0 & 3 & 3 & 3 & 2 & 0 & 3 & 3 & 3 & 2 & 0 & 3 & 2 & 2 & 2 & 0 & 3 & 2 & 2 & 2 & 0 & 3 & 1 & 1 \\
\hline
\end{tabular}

Table 5 Land use of the watershed of different segments of River Serio. "Other - possible stressors" are land uses that could hypothetically cause impacts but are not considered in this paper.

\begin{tabular}{cccccccccccc} 
& \multicolumn{3}{c}{ Rs 1 } & \multicolumn{2}{c}{ Rs 2 } & \multicolumn{2}{c}{ Rs 3 } & \multicolumn{2}{c}{ Rs 4 } & \multicolumn{2}{c}{ Rs 55 } \\
\cline { 2 - 11 } & Area (ha) & $\%$ & Area (ha) & $\%$ & Area (ha) & $\%$ & Area (ha) & $\%$ & Area (ha) & $\%$ \\
\cline { 2 - 11 } Agriculture & 0.3 & 0.01 & 5 & 0.03 & 435 & 1.25 & 18399 & 64.66 & 10385 & 53.18 \\
Industry & 0 & 0 & 6 & 0.04 & 705 & 2.03 & 1905 & 6.69 & 555 & 2.84 \\
Urban & 32 & 0.54 & 176 & 1.12 & 2308 & 6.64 & 3547 & 12.47 & 1588 & 8.13 \\
Other - Poss. Stres. & 1 & 0.01 & 3 & 0.02 & 169 & 0.49 & 818 & 2.88 & 193 & 0.99 \\
Other - No Stressor & 5966 & 99.45 & 15534 & 98.8 & 31151 & 89.6 & 3785 & 13.3 & 6808 & 34.86
\end{tabular}




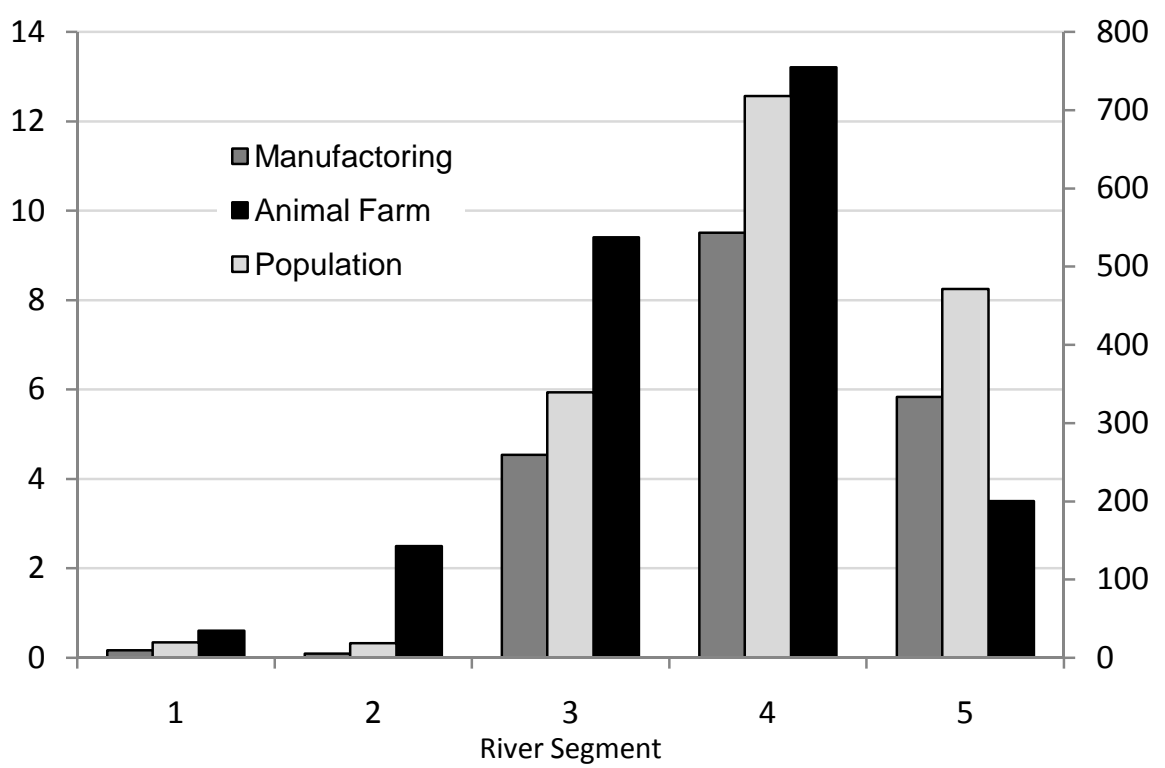

Figure 4 Density (number $/ \mathrm{km}^{2}$ ) of manufacturing activities, animal farms (left scale) and population (right scale) referred to each River Serio segment.

Hydromorphological - Water flow reduction is a known problem affecting all length of River Serio. Nevertheless, only a qualitative description of this driver has been provided, since no sound data about natural flow rate have been found. Water flow alteration is due to water withdrawals: 3 withdrawals are recorded in first r.s., 2 in the second, 19 in the third, 2 in the fourth and 4 in the fifth. Upstream (until r.s. 3 ) withdrawals are due to hydropower production, so water is returned downstream. From the second part of r.s. 3 withdrawals are due to irrigation, so water is not returned to the river. Major water flow alteration regards some parts of r.s. 4, that are often dry for several days a year. R.s. 5 shows less alteration because of the presence of some tributaries and springs.

To confirm the suitability of River Trebbia as a reference river, in Table 6, the number and typology of discharge points of the river are reported. Inhabitants in the watershed are $24500.90 \%$ of the households are connected to wastewater treatment plants. Considering a total amount of 44 industrial discharge points, they are mainly in the last segment of the river. Agriculture is present especially in the plain area (related to river segment 5). It must be noted that the $5^{\text {th }}$ r.s. probably suffers for some flow alteration due to water use in agriculture. So its use as reference system could be questionable.

Table 6 Number of discharge points, per typology, in the river segments of Trebbia (modified from ARPA 2008).

\begin{tabular}{lccc}
\hline \hline & $\begin{array}{c}\text { Total number of } \\
\text { discharge points }\end{array}$ & $\begin{array}{c}\text { Number of urban } \\
\text { discharge points }\end{array}$ & $\begin{array}{c}\text { Number of industrial } \\
\text { discharge points }\end{array}$ \\
\cline { 2 - 4 } Rs 1 and 2 & 174 & 174 & 0 \\
Rs 3 & 41 & 40 & 1 \\
Rs 4 & 62 & 44 & 18 \\
Rs 5 & 51 & 26 & 25
\end{tabular}

To get a semi-quantitative description of the intensity of stressors, a scoring system, functional to this particular case study is shown in Table 7. The scoring system (with the exception of hydromorphological stressor) was built on the basis of qualitative observations of minimum and maximum values on a European scale for each parameter. 
Table 7 Categorization of stressor indicators. Edge values are comprised in the major class. Classes 4 and 5 of hydromorphological stressor consider minimum flow requirements (MFR) as the last trigger.

\begin{tabular}{lllllll}
\hline \hline & 0 & 1 & 2 & 3 & 4 & 5 \\
\cline { 2 - 7 } Percentage of agricultural land use & $0-5$ & $5-15$ & $15-25$ & $25-50$ & $50-75$ & $>75$ \\
Animal farms density (farm/ $\mathrm{Km}^{2}$ ) & $0-1$ & $1-2$ & $2-3$ & $3-4$ & $4-5$ & $>5$ \\
Population density (inhabitants/Km ${ }^{2}$ ) & $0-100$ & $100-500$ & $500-1000$ & $1000-2500$ & $2500-5000$ & $>5000$ \\
Manufacturing activities / $\mathrm{Km}^{2}$ & $0-3$ & $3-7$ & $7-10$ & $10-20$ & $20-60$ & $>60$ \\
Flow rate variation (\%) & $0-10$ & $10-20$ & $20-40$ & $40-60$ & $60-\mathrm{MFR}$ & $>$ MFR
\end{tabular}

Table 8 shows the application of the scoring system to the different river segments of River Serio. Scoring of flow rate changes is based on qualitative information, as no quantitative data have been found.

Table 8 Magnitude of stressors in River Serio for each river segment.

\begin{tabular}{cccccc}
\hline \hline & 1 & 2 & 3 & 4 & 5 \\
\cline { 2 - 6 } & 0 & 0 & 1 & 3 & 1 \\
Urban - population density (inhabitants/ $\left./ \mathrm{Km}^{2}\right)$ & 0 & 0 & 1 & 2 & 1 \\
Industrial - $\left(\right.$ manufacturing activities $\left./ \mathrm{Km}^{2}\right)$ & 0 & 0 & 0 & 4 & 4 \\
Agriculture- percentage of agricultural land use & 0 & 1 & 3 & 4 & 2 \\
Agriculture- Animal farms density $\left(\mathrm{farm} / \mathrm{Km}^{2}\right)$ & 4 & 3 & 3 & 5 & 2 \\
Flow rate variation $(\%)$ & & & &
\end{tabular}

The combination of vulnerability related to each potential stressor and the magnitude of the stressors (considering the actual watershed conditions) lead to an evaluation of the potential alteration of a natural community in the river. This procedure was proposed to perform a preliminary validation of the presented methodology. Therefore, vulnerability scores (Table 4) may be multiplied times the stressor magnitude scores (Table 8), giving the results reported in Table 9. This table gives a semi-quantitative indication of the level of possible alteration produced by actual stressors on pristine macrobenthos community. A sum of all potential alteration for each river segment is also reported, in order to give an indication of the total pressure on the river segment. However, the total value must be taken with care, because effects of different stressors may not be additive.

By comparing community data in River Serio with those of River Trebbia (Table 3) and with potential alteration assessment (Table 9), the following comments can be made.

Table 9 Potential alteration in each River Serio segment.

\begin{tabular}{lrrrrr}
\hline & 1 & 2 & 3 & 4 & 5 \\
\cline { 2 - 6 } Urban & 0 & 0 & 11 & 30 & 7 \\
Industrial & 0 & 0 & 6 & 12 & 6 \\
Agricultural (crop) & 0 & 0 & 0 & 10 & 10 \\
Agricultural (farms) & 0 & 11 & 33 & 40 & 14 \\
Hydromorphological & 12 & 9 & 6 & 10 & 2 \\
\hline Total & 12 & 20 & 56 & 102 & 39
\end{tabular}

River segment 1 . The community appeared in good quality, as indicated by the high value of EBI and the presence of sensitive species. However a decrease of systematic units, in comparison with reference community may be related to a non-specific stressor, like flow rate alteration. 
River segment 2. Further reduction of systematic units and decrease of EBI value could be related to oxygen depletion due to the presence of animal farms.

River segment 3. This segment was represented by three sampling stations. However, the first one should be assumed as representative of conditions close to r.s. 2. In the other stations the quality of macrobenthos community substantially changed. All taxa particularly sensitive to oxygen concentration disappeared or reduced significantly while systematic units of other taxa remained more or less constant. This result fits well with the assessed influence of animal farms and urban stressor.

River segment 4. The community showed the biggest alteration with respect to the reference. The number of total systematic units decreased, reaching the lowest level of the entire river. EBI score was also the lowest. All the stressors reached the biggest score in this segment and each could have important effects on the community. Crustaceans appeared in this section, represented only by Asellidae, while in the reference community Gammaridae were also present. It is worth noting that Asellidae are very resistant to toxicity of some chemicals (e.g. insecticides) while Gammaridae are extremely sensitive (Bonzini et al. 2008; Sala et al. 2012).

River segment 5. The quality of the community in this segment is improved, as indicated by the slight increase of EBI and of the number of systematic units, as well as by the presence of some sensitive groups (Tricoptera, Gammaridae). Indeed, potential alteration substantially decreases for almost all stressors and is even lower than in segment 3 . However, it should be considered that the river represents a continuum, so the quality of this segment may be influenced by the very bad quality of the previous one.

\section{Discussion and conclusions}

As highlighted by De Lange et al. (2010) there is a lack of methods for assessing and quantifying ecosystem vulnerability to human stressors, suitable to be used in site-specific ecotoxicological risk assessment. This paper describes a first vulnerability indexing method for the aquatic environment, suitable to assess different stressors likely to occur in riverine ecosystems. In spite of some simplifications, the application of the method to a case study seems to provide satisfying results. The composition of the community of River Serio fits quite well with the predictions possible on the basis of the vulnerability of the reference community and of the intensity of stressors. However, it must be underlined that the described procedure represents a preliminary proposal that need to be refined and improved and needs additional information for a better quantitative estimation of the data to be used in the assessment. An overview of the major needs for more knowledge and information and of some conceptual drawbacks is given below.

1. All indicators based on scoring systems and synthetic algorithms suffer for a large margin of subjectivity and arbitrariness. Moreover, some of the assumptions and comments have been based on "expert judgements" of the authors and not on more or less codified evaluation approaches. The effectiveness and reliability of the vulnerability index of equation 2.1 , as well as of the whole procedure, must be validated and calibrated through the application on many other aquatic ecosystems with different characteristics and typologies. Moreover, some more scientifically-based procedures should be developed for the comparison of the structure of biological communities, in order to evaluate the significance of some observed changes.

2. The sensitivity of taxa to different stressors is a key point for estimating the sensitivity of the community. For the macrobenthos community, this is well known for oxygen content and some reliable information is available for some toxic chemicals, such as some insecticide classes (Bonzini et al. 2008; Sala et al. 2012). In this paper, the sensitivity to insecticides has been applied in general to toxic chemicals. It has been an arbitrary choice, due to the need to apply the procedure without sound scientific information available. More information is needed for a sound science-based knowledge on species sensitivity distribution to different stressors in aquatic communities.

3. Community vulnerability assessment has been mainly based on considerations on individual populations, in particular on these populations that are significant for a given stressor. However, most critical issues arise moving from population to community level. For none of the three considered components, community properties could be inferred from the sum of single population features. Emergent properties 
and indirect effects, due to complex relationships between different species in ecosystems, prevent the use of a reductionist approach in this phase. It is recognized that, up to date, our descriptive and predictive capability of ecological hierarchical levels is the lowest at the community level (van Straalen 2003). The implementation of tools capable to provide integrated responses at the community levels is a challenge for ecotoxicology in the next future.

4. Interaction must be taken into account not only at the population-community level, but also at the stressor level. Even if some pragmatic approaches can be proposed for mixtures of toxicants (Verro et al. 2009), the interaction of multiple stressors (physical, chemical, etc.) is far to be additive. More knowledge is needed for assessing cumulative effect of multiple stressors.

5. All simplified approaches like those described above, presume that the response of bio-ecological entities (individuals, populations communities) to a stressor follows a continuous trend (linear, logistic, exponential, etc.). However, discontinuous responses are possible. For example, the Rivet Hypothesis (Ehrlich and Ehrlich 1981) presumes that each loss of a species affects ecosystem integrity to a small extent; if too many rivets are lost, the system collapses. This confirms our lack of knowledge on community functioning.

6. Other approximations are referred to the specific case study. The description of driving forces, pressures and stressors has been strongly simplified. For example, for industry only chemical toxicity has been considered, whilst industrial pressure may be extremely variable as a function of industrial typology. This kind of detail requires a more careful assessment of land use and of activities in the watershed that was not the objective of this paper.

In spite of all these drawbacks, the method represents an attempt to estimate and to express in quantitative (numeric) terms a property of ecosystems extremely important for environmental protection and management, frequently overlooked risk assessment procedures.

Vulnerability assessment may also allow a better definition of Environmental Quality Standards of chemicals in surface water, as required by the WFD.

Comprehensive vulnerability assessment has to take into account all the potential stressors that may reach the water body as WFD addresses the potential ecological risk of all toxic chemicals. The proposed method allows considering the relative importance of a single stressor and the potential magnitude of the complex system of different stressors considering spatial differentiation.

Indeed, environmental risk assessment in the context of WFD is based on two assumptions: ecosystem sensitivity depends on the most sensitive species and protecting ecosystem structure protects community function (EC 2003).

Three main categories of effect could be taken into account for freshwater ecosystems: effect on ecosystem structure, ecosystem function, aesthetic and economic values. Therefore, ecological protection goals have to be fixed in order to guarantee also ecosystem services provided by the aquatic ecosystems.

Furthermore, sustainability of freshwater ecosystems involve not only their ecological properties but also their economic and social function and imply also the need of assigning to ecological vulnerability an assessment of economic and social issues, related to ecosystem capability of providing ecosystem services and their related economic and social values (Brock et al. 2006).

The ecosystem services and values assessment represent a relevant tool for addressing risk management. According to Brock et al. (2006), the following ecological impacts may be considered important from a scientific and stakeholder point of view: decrease in biodiversity; impact on ecosystem functioning; decrease in perceived aesthetic value and functionality to humans. The same authors also underline the relevance of spatio-temporal differentiation in ecological protection goals and propose the harmonisation of the different scientific approaches for ecotoxicological risk assessment adopted in guidance documents. A differentiation in the protection level of aquatic habitats, related to the level of vulnerability, may contribute to a more focused risk assessment that takes into account perceived difference in functionality and intrinsic value of surface water. 


\section{References}

ARPA Emilia Romagna (2008) Studio del bacino idrografico del Fiume Trebbia per la gestione sostenibile delle risorse idriche. Sintesi tecnica. Arpa Emilia Romagna, pp 180.

ARPA Lombardia (2009) Monitoring data from the Regional Environmental Protection Agency.

ARPA Emilia Romagna (2009) Monitoring data from the Regional Environmental Protection Agency.

Baird DJ, Van den Brink PJ (2007) Using biological traits to predict species sensitivity to toxic substances. Ecotoxicology and Environmental Safety 67: 296-301.

Bonzini S, Berra E, Forcella M, Parenti P, Vighi M (2008) Impact of pesticides on natural macrozoobenthos communities in surface water. Aquatic Toxicology 89: 1-10.

Borja A, Galparsoro I, Solaun O, Muxika I, Tello E M, Uriarte A, Valencia V (2006) The European Water Framework Directive and the DPSIR, a methodological approach to assess the risk of failing to achieve good ecological status. Estuarine, Coastal and Shelf Science 66: 84-96.

Brock TC, Arts GH, Maltby L, Van den Brink PJ (2006) Aquatic Risks of Pesticides, Ecological Protection Goals, and Common Aims in European Union Legislation. Integrated Environmental Assessment and Management 2: 20-46

De Lange HJ, Sala S, Vighi M, Faber JH (2010) Ecological vulnerability in risk assessment - a review and perspectives. Science of the Total Environment 408(18): 3871-3879.

Dimitrov S, Mekenyan OG, Schultz TW (2000) Interspecies modeling of narcotics toxicity to aquatic animals. Bulletin of Environmental Contamination and Toxicology 65: 399-406.

EC (1991) Directive 91/414/EEC of 15 July 1991 concerning the placing of plant protection products on the market. Off J Eur Commun L 230, 19/8/1991.

EC (2000) Directive 2000/60/EC of the European Parliament and of the Council of 23 October 2000 establishing a framework for Community action in the field of water policy. Off J Eur Commun L $327 / 1,22 / 12 / 2000$.

EC (2003) Common Implementation Strategy for the Water Framework Directive (2000/60/EC). Guidance Document No 10. Rivers and Lakes - Typology, Reference Conditions and Classification Systems. Luxembourg: Office for Official Publications of the European Communities, 2003.

EC (2006) EC. Regulation (EC) No 1907/2006 of the European Parliament and of the Council concerning the Registration, Evaluation, Authorisation and Restriction of Chemicals (REACH), establishing a European Chemicals Agency, amending Directive 1999/45/EC and repealing Council Regulation (EEC) No 793/93 and Commission Regulation (EC) No 1488/94 as well as Council Directive 76/769/EEC and Commission Directives 91/155/EEC, 93/67/EEC, 93/105/EC and 2000/21/EC. Off J Eur Commun L 396/1, 30/12/2006.

EEA. European Environment Agency. The DPSIR framework used by the EEA, http://glossary.eea.europa.eu/terminology/sitesearch?term=dpsir, accessed July 2009.

Ehrlich PR, Ehrlich AH (1981) Extinction. The causes and consequences of the disappearance of species. Random House, New York (NY), 305 pp.

FOCUS (2002) surface water scenarios in the EU evaluation process under 91/414/EEC. Report prepared by the FOCUS Working Group on Surface Water Scenarios, EC Document Reference Sanco/4802/2002; $221 \mathrm{pp}$.

Huet M (1949) Apercu des relation entre la pente et les population piscicoles des eaux courantes. Vol XI, Verlag Birkhuser, Basel, Schweiz, pp. 332-351.

Posthuma L, Suter GW, Traas TP (2002) Species Sensitivity Distribution in Ecotoxicology. Lewis Publishers, Boca Raton, pp. 587.

Provincia di Bergamo (2001) Carta delle Vocazioni Ittiche.

Provincia di Genova (2003) Carta Ittica - indagini di aggiornamento 1999-2003. 
Regione Lombardia (2009) Dusaf, - Destinazione d'Uso dei Suoli Agricoli e Forestali. website http://www.cartografia.regione.lombardia.it. (Accessed 01.07.2009).

Sala S., Vighi M (2008) GIS-based procedure for site-specific risk assessment of pesticides for aquatic ecosystems. Ecotoxicology and Environmental Safety 69: 1-12.

Sala S, Vighi M (2012) SSD-based rating system for the classification of pesticide risk on biodiversity. Ecotoxicology, in press. DOI:10.1007/s10646-012-0858-7

Stanners D, Bosch P, Dom A, Gabrielsen P, Gee D, Martin J, Rickard L, Weber JL (2007) Frameworks for environmental assessment and indicators at the EEA. In: Hak T, Moldan B, Dahl AL. (Eds.), Sustainability Indicators. A Scientific Assessment. InIsland Press, Washington, pp. 127-144.

Tremolada P, Finizio A, Villa S, Gaggi C, Vighi M (2004) Quantitative inter-specific chemical activity relationships of pesticides in the aquatic environment. Aquatic Toxicology 67: 87-103

Van Straalen NM, Denneman CAJ (1989) Ecotoxicological evaluation of soil quality criteria. Ecotoxicology and Environmental Safety 17: 190-204.

Van Straalen NM (2003) Ecotoxicology becomes stress ecology. Environmental Science and Technology 37: 325-330.

Vannote RL, Minshall GW, Cummins KW, Sedell JR, Cushing CE (1980) The river continuum concept. Canadian Journal of Fisheries and Aquatic Sciences 37: 130-137.

Verro R, Finizio A, Otto S, Vighi M (2009) Predicting pesticide environmental risk in intensive agricultural areas. II: screening level risk assessment of complex mixtures in surface waters. Environmental Science and Technology 43: 530-537.

Woodiwiss FS (1964) The biological system of stream classification used by the Trent River Board. Chemistry and Industry 14: 443-447.

Wright JF, Sutcliffe DW, Furse MT (2000) RIVPACS and other techniques. The Freshwater Biological Association, Ambleside, Cumbria, UK. 